\title{
The Ecological Significance of Pubescence in Saussurea medusa, a High-Elevation Himalayan "Woolly Plant"
}

\author{
Yang Yang*† \\ Christian Körnerłฐ and \\ Hang Sun*§ \\ * Key Laboratory of Biodiversity and \\ Biogeography, Kunming Institute of \\ Botany, Chinese Academy of Sciences, \\ 132 Lanhei Road, 650204 Kunming, \\ Yunnan, People's Republic of China \\ $\dagger$ Graduate School of the Chinese \\ Academy of Sciences, 100039 Beijing, \\ People's Republic of China \\ \#nstitute of Botany, \\ University of Basel, \\ Schönbeinstrasse 6, CH-4056 Basel, \\ Switzerland. \\ $\S$ Corresponding authors: \\ hsun@mail.kib.ac.cn; \\ ch.koerner@unibas.ch
}

\begin{abstract}
Several members of the vascular plant genus Saussurea, which are found at elevations exceeding $5000 \mathrm{~m}$, have dense layers of woolly trichomes on their leaves, bracts, and inflorescences, the function of which is not fully understood. Here we explore the thermal benefits of pubescence in Saussurea medusa, both in situ in the Chinese Hengduan Mountains and under controlled conditions. Mean daytime inflorescence temperature was $5.9 \mathrm{~K}$ above air temperature. Pubescence removal revealed that most of this warming is not related to pubescence but to radiant warming of the compact inflorescence itself $(4.1 \mathrm{~K}$ warming in shaved plants, i.e. $1.8 \mathrm{~K}$ less). The effect of pubescence on nighttime radiative cooling was negligible. Our data indicated that the functional role of pubescence in these high-elevation plants cannot be attributed solely to producing warming tissues, but may also include other functions such as water repellency and reflection of short peaks of high radiation. These other functions must be specific to a small group of species, given that most other high elevation taxa do not exhibit this woolly character.
\end{abstract}

\section{Introduction}

Highly pubescent ("woolly") plants are thought to represent an evolutionary response to either very high (e.g. desert shrubs) or very low temperatures (alpine plants in open rock and scree fields) (Ehleringer, 1981; Ehleringer and Mooney, 1978; Tsukaya et al., 2002). However, counter to common belief, pubescence is not very common in either of these extreme environments, and rather represents a noteworthy exception (Körner, 2003). Well-known examples of high pubescence are the tropical giant rosettes above tree line in Africa and the equatorial Andes. These exceptional plants have been shown to benefit in various ways from a covering of dead trichomes, often much thicker than the actual leaf (Körner, 2003; Beck et al., 1980). A number of alpine taxa produce smaller, but still upright growth forms which emerge from otherwise narrow, low stature vegetation carpets dominating the highest elevations. Some of these mostly herbaceous plants also are densely pubescent, conferring unknown functional benefits. Examples are found in Lupinus and Culcitium in the equatorial Andes, Anaphalis species in New Guinea (Ch. Körner, personal observations), and the genus Saussurea occurring at some of the highest elevations of any vascular plant (e.g. Saussurea gnaphalodes in the vicinity of Mount Everest at $6400 \mathrm{~m}$ as recorded by E. Shipton in Miehe, 1991, and Yoshida, 2002).

Many of the high-altitude Saussurea are known for their spectacular pubescence (Fig. 1a). The water repellency of these hydrophobic structures may prevent surface wetting and pathogen infection during the wet monsoonal period (Levin, 1973; Brewer and Smith, 1997). The pubescence may also deter herbivores (Woodman and Fernandez, 1991). Another possible function is modification of plant tissue temperature (Ohba, 1988). The present study explored the possibility that one of the most prominent representatives of the pubescent members of the genus Saussurea obtains thermal advantages from the pubescence.
Several species of "woolly" plants are called "snowball" plants (Ohba 1988), or "downy" plants (Tsukaya and Tsuge, 2001) and can be found in the alpine zone of the Eastern Himalaya and the Hengduan Mountain region of SW China. In addition to low air temperatures and short growing seasons, this region also experiences monsoonal midsummer rainfall, with regular leaf wetting, interrupted by short periods of very intense solar radiation (Yoshida, 2002).

Belonging to the subgenus Eriocoryne, Saussurea medusa forms low-stature rosettes in the vegetative phase, but flowering individuals can be 10-15 cm tall (Ohba, 1988; Fujikawa and Omori, 2000; Yang and Sun, 2006; Fig. 1b). These plants are found isolated on barren, high-elevation scree or rock fields, but the actual benefits of pubescence have not yet been explored. These "woolly" plants have attracted the attention of biologists for many years (see also Tsukaya and Tsuge, 2001). The highly pubescent bracts of this species may facilitate growth by decoupling tissue and air temperatures of the upright structures. The growth of the stalk probably plays an important role in attracting pollinators, and has a positive effect on seed set and dispersal (e.g. Werner, 1976; Hainsworth et al., 1984; Obeso, 1993; Muchhala and Jarrin, 2002).

It is well established that low-growing plants experience warmer growth temperatures relative to upright species (Körner and Cochrane, 1986; Körner, 2003). In contrast, plants with an upright growth form are more closely coupled to ambient atmospheric conditions, potentially explaining their rarity at the highest altitudes where vascular plants are found, with the few noteworthy exceptions mentioned above.

The thermal consequences of pubescence have been studied primarily in desert ecosystems. Pubescence has been reported to increase reflectance and lower temperature in Encelia farinosa (Ehleringer et al., 1981) and Verbascum thapsus (Parkhurst, 1976). In these desert plants, trichomes commonly form highly reflectant 

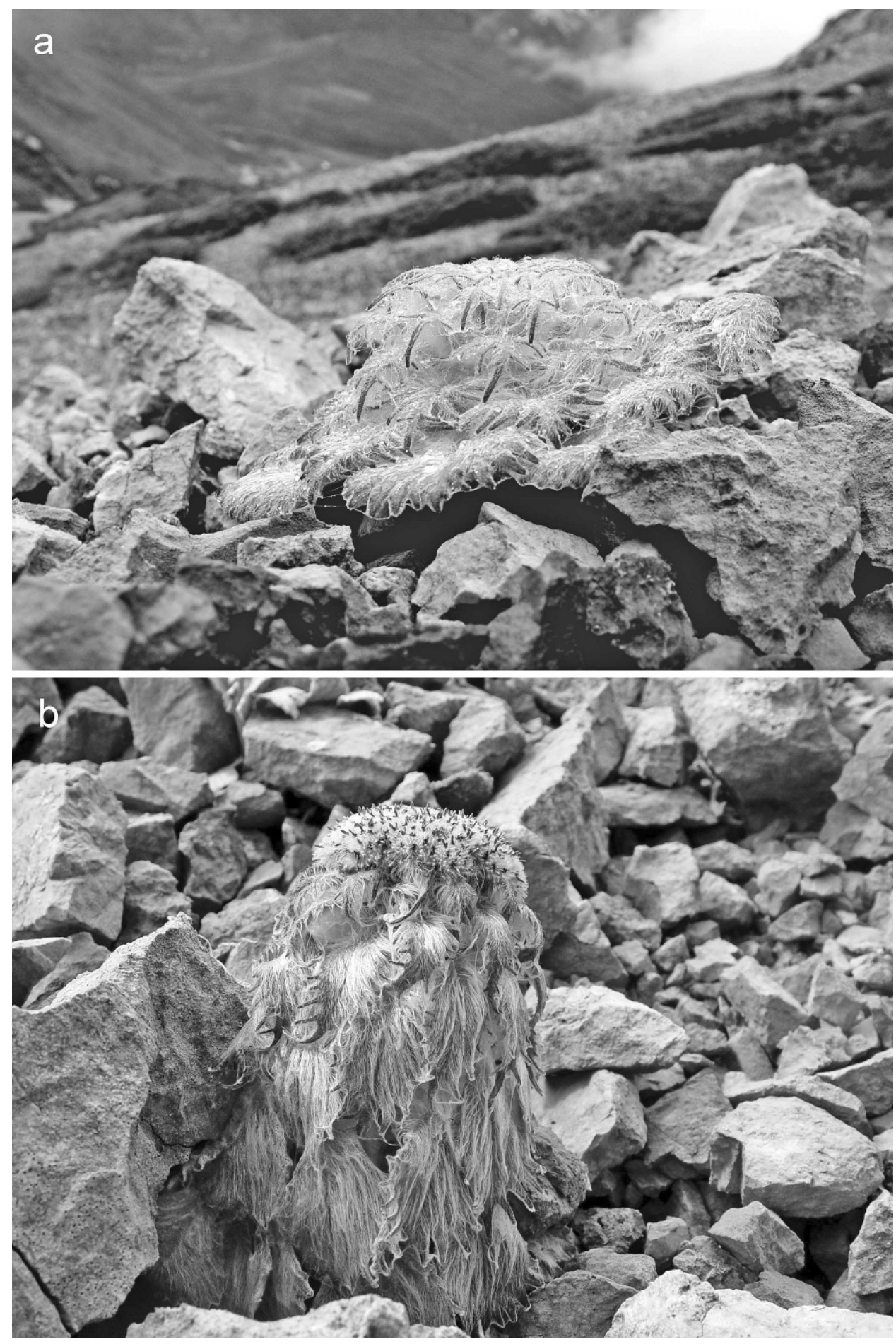

FIGURE 1. (a) Inflorescence of Saussurea medusa under dense, hairy bracts in the vegetative stage and (b) in the flowering stage. layers, narrowly attached to the leaf surface. In contrast, pubescent plants from cold environments often form a thick leaf cover of woolly trichomes, the white color of which may reflect transmissivity needs of photosynthesis, whereas a purely thermal advantage would select for darker structures. Many alpine flowers have dark central parts and perform solar tracking to accumulate heat (e.g. Totland, 1996; Luzar and Gottsberger, 2001; Galen, 2006). Some high Andean and Himalayan pubescent taxa have dark-colored flowers (Valeriana sp. at 4600 m, NW Argentina; Saussurea gnaphalodes at $>6000 \mathrm{~m}$, Himalaya). The exceptional pubescence of $S$. medusa covers inflorescences, and may thus be associated with reproductive advantages. Pubescence could also screen sensitive floral tissue from nighttime radiative cooling (Tsukaya and Tsuge, 2001). The woolly cover of flowers may offer a micro-refuge for pollinators during windy and cold weather conditions, thus facilitating reproduction of the plants (Tsukaya et al., 2002; Yoshida, 2005).

The dense pubescence of $S$. medusa could prevent either overheating by enhanced reflectance of radiation or establish an aerodynamic barrier that servers as a heat trap without screening too much photosynthetically active radiation. Given the low air temperatures in its high-elevation habitat, we hypothesized that the function of the pubescence is to warm the tissues of the plant. To test this hypothesis we present in situ and laboratory data, including pubescence removal experiments. 


\section{Materials and Methods}

\section{PLANT SPECIES}

The genus Saussurea is distributed mainly in the temperate and subarctic regions of Eurasia and consists of about 400 species classified into 6 subgenera. Saussurea medusa Maxim. (Asteraceae) is a perennial herbaceous plant of up to $15 \mathrm{~cm}$ height with a relatively large rhizome system, growing at elevations between 3800 and $5000 \mathrm{~m}$ in the Sino-Himalayan region. S. medusa is monocarpic (personal observations). Bumblebees (Bombus chinensis Motawitz) were the primary, if not sole, pollinator of $S$. medusa (Tsukaya et al., 2002). Voucher specimens were collected and deposited in the herbarium of the Kunming Institute of Botany of the Chinese Academy of Sciences (KUN).

\section{STUDY SITE AND CLIMATE}

Field measurements were carried out in the native habitat of Saussurea medusa, the alpine zone of Baima Snow Mountain, De Qin County, Yunnan Province, SW China $\left(28^{\circ} 23^{\prime} \mathrm{N}, 9^{\circ} 01^{\prime} \mathrm{E}\right.$, between 4550 and $4620 \mathrm{~m}$ ). Generally, the climate of this region is characterized by summer monsoon (Zhang, 1998). The mean air temperature at the study site in summer was extrapolated from the closest climate station (Deqin meteorological station, $28^{\circ} 29^{\prime} \mathrm{N}$, $98^{\circ} 55^{\prime} \mathrm{E}, 3320 \mathrm{~m}$ ) using an adiabatic lapse rate of $0.60 \mathrm{~K}$ per $100 \mathrm{~m}$. The difference in mean monthly temperature between the coldest and warmest month is around $15 \mathrm{~K}$. The growing season lasts between 10 and 12 weeks. The mean annual precipitation of 800-850 mm falls mainly between July and September.

All measurements presented here were obtained between late June (25-30) and early July (1-2) 2006. Additionally, we also compared flower temperature with and without hairy bracts in the field in July (8-13, 28-31) and early August (1-2) 2005.

Flower temperature was defined as the internal flower tissue temperature at the ovary $(5-10 \mathrm{~mm}$ below the surface of the inflorescence) and was measured using two 4 channel thermocouple data loggers (Center 309, data logger thermometer, Center Technology Corp., Taiwan, China) equipped with 4 alloy needle type sensor probes (1.0 to $1.6 \mathrm{~mm}$ diameter and an active tip length of $5 \mathrm{~mm}$ ). These 8 probes were calibrated in ice water before use, which confirmed stability and absolute accuracy (deviation from zero $<1.0 \mathrm{~K}$, commonly $<0.7 \mathrm{~K}$ ).

In order to separate stature/architecture effects from pubescence effects, we removed the hairy bracts in some individuals $(n=$ 3 ) and compared their inflorescence temperature with untreated control plants $(n=3$, plus unreplicated data from 2005). Air temperature $\left(\mathrm{T}_{\mathrm{a}}\right)$, relative humidity $(\mathrm{rh})$, and solar radiation (l) at the height of the inflorescence (ca. $10 \mathrm{~cm}$ above ground) were recorded at 30 second intervals $\left(\mathrm{T}_{\mathrm{a}}\right.$ and $\mathrm{rh}$ under a reflective screen by an electric humidity sensor with an integrated thermistor and a pyranometer, all connected to data loggers (TES 1365 and TES 1336A, TES Corp., Taiwan, China) during summer. Wind velocity $10 \mathrm{~cm}$ above ground was recorded with a recording anemometer every $150 \mathrm{sec}$ (AVM-07, Prova Corp., Taiwan, China).

\section{LABORATORY MEASUREMENTS}

\section{Energy Budget and Spectral Reflectance of Bracts}

In addition to field measurements, we explored the thermal effects of pubescence following an abrupt change in irradiation in the laboratory. Twenty individual plants were transported to the laboratory in an insulated ice box within 24 hours and kept at $<5^{\circ} \mathrm{C}$. To compare bracts with and without hairs, we gently
TABLE 1

Daytime (7:00-20:00 h) data of mean, maximum, and minimum air temperature $\left(T_{a}\right) 10 \mathrm{~cm}$ above ground, solar radiation (I), relative humidity (rh), and wind velocity (v) during the experimental period in the field (6 days in total) in 2006. Means presented in the table are for $\mathbf{1 3}$ hours of $30 \mathrm{sec}$ recording (wind velocities were recorded at $150 \mathrm{sec}$ interval) values for 6 days. Weather conditions during the 6 days included one sunny day, two cloudy days, and three cloudy days with some rain.

\begin{tabular}{lcccl}
\hline \hline & $\mathrm{T}_{\mathrm{a}}\left({ }^{\circ} \mathrm{C}\right)$ & $\mathrm{I}(\mathrm{kLux})$ & $\mathrm{rh}(\%)$ & $\mathrm{V}\left(\mathrm{m} \mathrm{s}^{-1}\right)$ \\
\hline Mean & $8.9 \pm 3.2^{*}$ & $18.9 \pm 15.7$ & $78 \pm 13.6$ & $0.4 \pm 0.5$ \\
Maximum & 19.7 & 101 & 100 & 2.7 \\
Minimum & 1.5 & 0 & 41.9 & 0 \\
\hline
\end{tabular}

* Standard deviation for 6 daily means.

removed hairs on the bracts with sticky tape. Subsequent examination of the bract surface by microscope assured us that the removal of hairs caused no visual wounds. Bracts were excised under water. Pairs of bracts were then placed in a plastic wind tunnel with a constant wind velocity of $3.0 \mathrm{~m} \mathrm{~s}^{-1}$. We then successively exposed these bracts to unfiltered light from three lamps with different power (Standard A-shape clear, incandescent lamp, $40 \mathrm{~W}, 60 \mathrm{~W}, 100 \mathrm{~W}$, Philips Lighting Corp., China) which were $50 \mathrm{~cm}$ above the bracts for 10 to 15 minutes. The bract temperatures were recorded in $30 \mathrm{sec}$ intervals with the same data acquisition system that was used in the field, but using $0.1 \mathrm{~mm}$ temperature sensors mounted to the lower leaf surface of the bracts with a porous white sticky tape $(5 \times 5 \mathrm{~mm})$. Eight bracts were chosen from 4 individuals to compare bract temperature with and without hairs. Radiative reflectance of bracts with and without hairs between 300 and $800 \mathrm{~nm}$ was measured with a spectral analysis system (Unispec-sc, PP Systems Inc., Hitchin, Hertfordshire, U.K.) on 20 bracts from 5 individuals.

\section{Statistical Analysis}

Air and flower temperature data were log transformed in order to meet the requirements of normal distribution. The correlations between air and plant temperatures with incoming radiation were tested using a Spearmen test. The temperature difference between bracts with and without hairs under various radiation loads was tested with a paired-sample $T$-test. The number of replications always refers to the number of plants tested. Statistics were performed with SPSS (version 13.0, SPSS, Chicago, U.S.A.).

\section{Results}

\section{AMBIENT CLIMATE DURING THE FIELD CAMPAIGN}

During the study period the prevailing weather was cloudy, with brief periods during which photon flux density peaked at more than $2000 \mu \mathrm{mol} \mathrm{m}{ }^{-2} \mathrm{~s}^{-1}$ (with the exception of the afternoon of 1 July, which was bright throughout; Table 1). Mean air temperature scaled from the nearest meteorological station was $5.6^{\circ} \mathrm{C}\left(\min . / \max .1 .1 / 12.8^{\circ} \mathrm{C}\right)$ in June and $7.4^{\circ} \mathrm{C}(\min . / \max .3 .3 /$ $11.9^{\circ} \mathrm{C}$ ) in July 2006 . Ambient humidity was quite high because of the monsoonal summer climate during the study period. Wind speed was generally low. Air temperatures at $10 \mathrm{~cm}$ above ground closely correlated with incoming radiation $\left(\mathrm{r}^{2}=0.82\right)$, which illustrates the general radiative warming of the air around vegetation (near the ground) in this environment. 
TABLE 2

The temperature regime in intact and shaved inflorescences and air temperatures at the height of the inflorescence during the experimental period in 2006.

\begin{tabular}{|c|c|c|c|c|c|c|}
\hline & \multicolumn{3}{|c|}{ Day } & \multicolumn{3}{|c|}{ Night } \\
\hline & Air & Control & Shaved & Air & Control & Shaved \\
\hline Mean & $8.9 \pm 3.2^{*}$ & $14.8 \pm 7.5$ & $13.0 \pm 7.0$ & $4.2 \pm 1.5$ & $3.3 \pm 2.4$ & $3.2 \pm 2.1$ \\
\hline Absolute Maximum & 19.7 & 32.1 & 34.9 & 10.9 & 25.0 & 22.5 \\
\hline Absolute Minimum & 1.5 & -1.0 & 0.9 & 0.8 & -1.5 & -1.4 \\
\hline
\end{tabular}

* All $30 \mathrm{sec}$ readings between 7:00 and 20:00 h, i.e. 1560 readings per day yield one daily mean, min, max. The repetition over six days yields six values for mean, min., max. Of these, the six means were averaged and presented with s.d. for $\mathrm{n}=6$, whereas the minima and maxima are presented as absolute extremes (the single highest and lowest reading).

\section{PLANT TEMPERATURES IN THE FIELD}

In 2006, inflorescences averaged $5.9 \mathrm{~K}$ above adjacent $(10 \mathrm{~cm})$ air temperature during the day (from 7:00 to 20:00 h). Removing hairs from the inflorescence reduced this effect to $4.1 \mathrm{~K}$, with the pubescent inflorescences $1.8 \mathrm{~K}$ warmer than shaved ones (Table 2). Periodic measurements in 2005 showed flower temperatures of an untreated plant were $1.6 \mathrm{~K}$ higher than a shaved one. The field temperature data indicate the following: (1) Inflorescence warming peaked at noon, when it was $10.6 \mathrm{~K}$ above air temperature $(7.3 \mathrm{~K}$ in shaved inflorescences, i.e. a short- term maximum difference of $3.3 \mathrm{~K}$ ). (2) The correlation between inflorescence temperature and solar radiation was almost identical in controls and treated inflorescences $\left(\mathrm{r}^{2}=0.84\right.$ vs. 0.85). (3) Temperature fluctuated less (smaller amplitude) in controls than in shaved inflorescences when radiation changed abruptly during intermittent cloudiness. (4) The treatment effect became smaller under drier, high-irradiance conditions (30 vs. 28 June; Fig. 2). (5) Nighttime temperatures differed little between treatments. (6) However, immediately after sunset, pubescent inflorescences stored more heat (ca. 2-2.5 K) until at least $1 \mathrm{~h}$ after sunset, whereas shaved inflorescences rapidly reached temperatures close

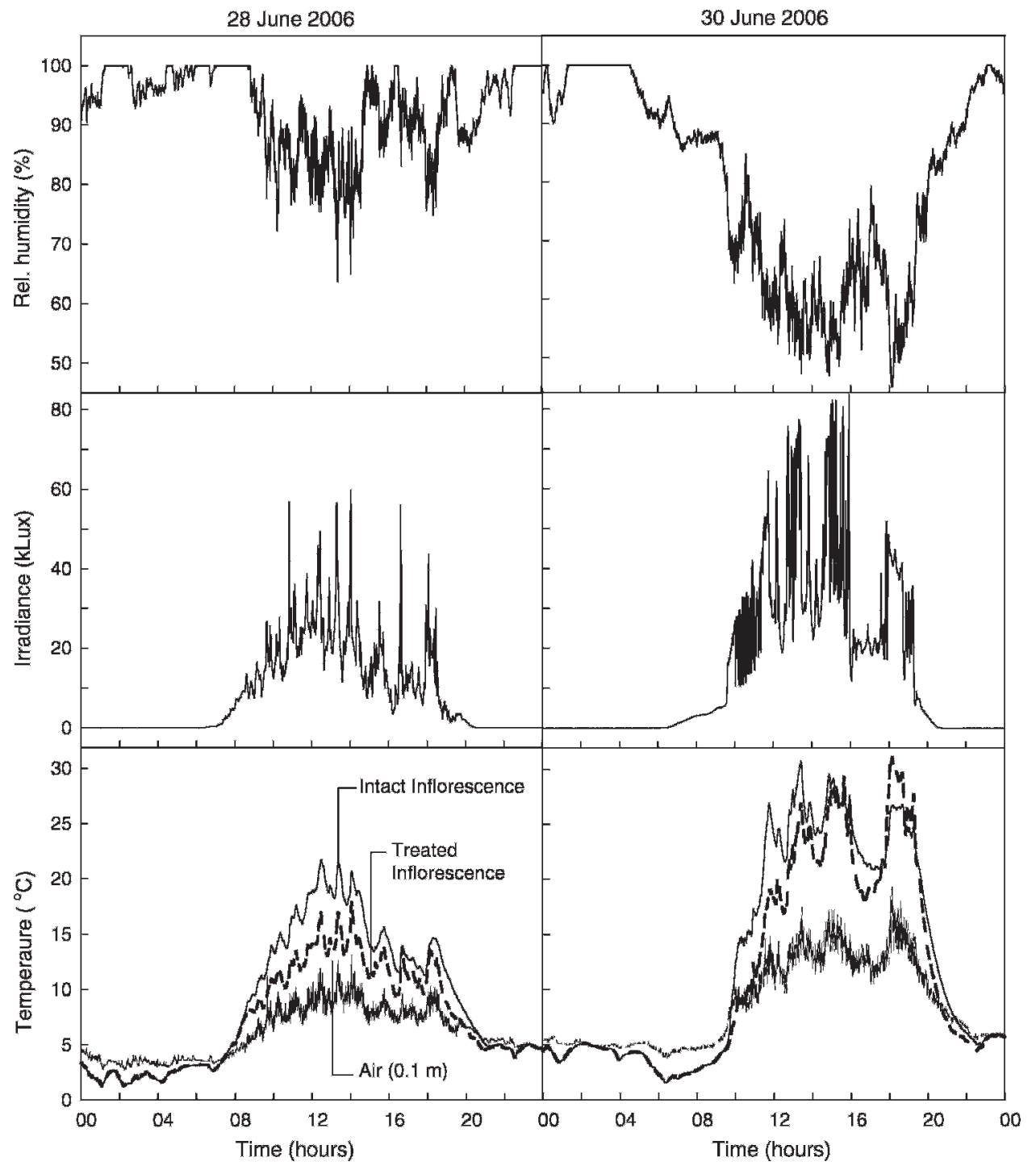

FIGURE 2. Diurnal course of environmental variables and temperature of control and "shaved" inflorescence $(n=3)$ under representative summer weather conditions for this region. Left: a cloudy day with short rain events. Right: a dry, cloudy day. Upper: relative humidity $(\%)$. Middle: radiation (kLux). Lower: temperature $\left({ }^{\circ} \mathrm{C}\right)$ in untreated and "shaved" inflorescences and air temperature in the immediate vicinity of inflorescences $10 \mathrm{~cm}$ above the ground. Flower temperatures plotted represent mean values for 3 flowers of each plant category. 


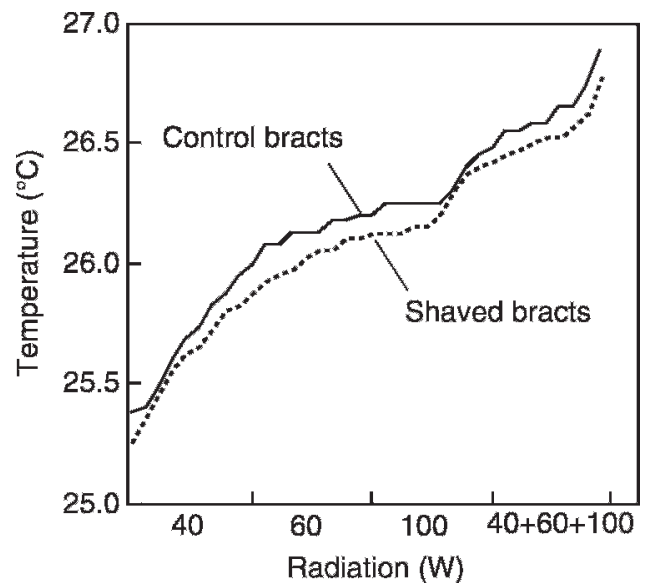

FIGURE 3. Temperature of untreated and shaved bracts under artificial irradiance in the laboratory (means for 8 bracts each).

to air temperature. Hence, during this period pubescence extends the warmer daytime conditions. The data illustrate that the major warming effect within the inflorescence $(5-8 \mathrm{~K})$ results from its overall compact nature and size, plus its dark color. Pubescence adds to this approximately $1-4 \mathrm{~K}$ warming.

\section{LABORATORY EXPERIMENTS}

Heat loading in a wind tunnel: Temperatures of untreated and treated (shaved) bracts differed little (but significantly) when receiving different radiation loads in a wind tunnel. Shaved bracts were cooler, with a maximum difference of $0.5 \mathrm{~K}(P=0.01$; Fig. 3$)$.

Spectral properties of pubescence: Reflectance of bracts with a natural hair cover ranged between 20 and $40 \%$ across the visible part of the spectrum (400-700 nm; Fig. 4). Removal of pubescence from the bract surface roughly halved reflectance (reductions by 30 to $70 \%$ ) in this spectral region. In the UV range this difference disappears.

\section{Discussion}

Overall, our results confirm the hypothesis of a warming effect of pubescence on the inflorescence of $S$. medusa. The situation may be similar to that in catkins of subarctic willows (Salix sp.) and Magnolia sp. where the shiny hairs seem to exert a similar function (Krog, 1955; Tsukaya and Tsuge, 2001). However, the contribution of pubescence to overall inflorescence warming above air temperature was much smaller than expected, and the major warming appears to result from the compact structure and dark color of inflorescences in this species (Wolpert, 1962). In fact, when exposed to radiative conditions in the laboratory under exceptionally high temperatures, pubescence had a cooling effect as was described earlier for desert plants (Ehleringer et al., 1976). While the overall inflorescence warming clearly results from an interaction between solar radiation and the solid part of the flowering head, the pubescent bracts add an aerodynamic resistance to the dissipation of heat. This aerodynamic effect is surprisingly small, but may still be of ecological importance. However, since other plants in this environment thrive without such a "coat," additional explanations for the functional role of extreme pubescence in this environment are needed.

We suggested that pubescence in $S$. medusa acts both as a heat trap as well as a buffer against rapid fluctuations of temperature. There was no apparent screening effect against radiative cooling at night, and hence the hypothesized protection against radiative

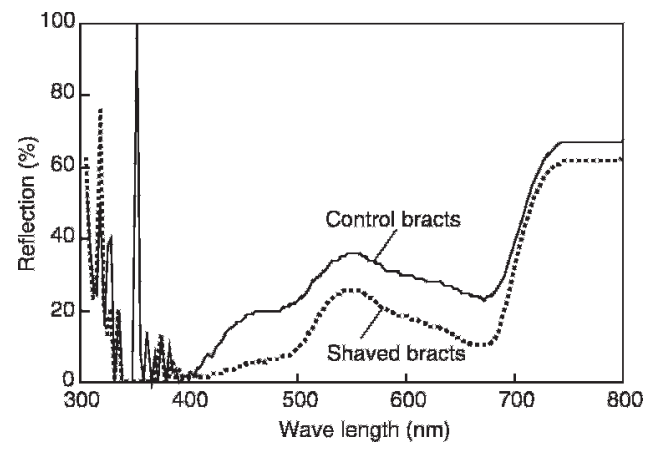

FIGURE 4. Reflectance of the upper surface of Saussurea medusa bracts before and after hair removal (mean for 20 bracts each).

freezing seems small. In some Afro-alpine giant rosette species, pubescence contributes to the insulative effect of nighttime closure of rosettes and thus exerts a protective function (Hedberg, 1964; Miller, 1986). Meinzer and Goldstein (1985) suggested that only massive plant organs with a high heat capacity could show considerable delay in cooling, such as that found in rosettes of Lobelia keniensis (Beck et al., 1980). Azorella compacta, a giant cushion plant in the southern Andes has a thin leaf layer directly overtopping massive woody structures which are able to store heat (Kleier, 2001). Similarly, Puya in the Ecuadorian Andes nests reproductive organs in very dense pockets of pubescent structures (Miller, 1986). It seems that pubescence in combination with plant tissues with high heat capacity underneath, slows nighttime cooling and reduces the risk of radiative freezing in these plants. However, we did not observed such nighttime freezing conditions in $S$. medusa.

Because of the monsoonal summer weather, nighttime air temperatures in the habitat of $S$. medusa were never below freezing during the June and July experimental period, when inflorescences were under full cover by pubescent bracts. Radiative freezing may be a rare situation for $S$. medusa in the study area, and should it occur, the deeply sunken ovaries would still be well protected by the dense 1- to 2-cm-thick petal and pappus layer. Only in September do plants experience freezing as the monsoonal rains cease. By that time seeds have matured, and plants senescence has occurred (personal observations). Chen and $\mathrm{Lu}$ (2002) have shown in callus and cell suspension cultures of adult leaves of $S$. medusa that these tissues can survive $-5^{\circ} \mathrm{C}$, lower than the temperature experienced during the growing season.

Very much like in $S$. medusa, pubescence has been found to be hydrophobic in other alpine taxa such as in tropical Espeletia species, preventing leaf surfaces from wetting, perhaps protecting stomata from occlusion by liquid water or restricting fungal pathogen attacks (Körner 2003). Reduced wettability by dense trichomes layers has also been shown for Pedicularis kanei, a plant that resembles the woolly plant appearance of the Himalayan regions well (Pandey and Nagar, 2003). The pubescence may be an invariant feature of $S$. medusa, conferring less of an advantage in the range we studied relative to other areas such as the northern part of Qinghai-Tibet plateau, where this plant is subjected to a cold and much more arid climate. Further studies addressing the influence of woolly hairs on the wettability of leaves or bracts and the functional consequences are needed to more fully understand the high degree of pubescence found in S. medusa.

\section{Acknowledgments}

This study was supported by grants from the National 973 Project (2003CB415103), Chinese Natural Science Foundation 
(CNSF grant numbers 40332021, 40771073, 30625004, and 30420120049 to H. Sun) and Yunnan Provincial Government through an Award for Prominent Contributions in Science and Technology to Prof. Wu Zheng-Yi in 2001 (KIB-WU-02 to H. Sun). We thank Susanna Peláez-Riedl (Basel) for her help with diagrams. W. D. Bowman (Boulder) and S. B. Zhang and W.Q. Li (Kunming) are thanked for their constructive comments on our writing and the experimental design. We are also grateful to K. F. Cao and Y. J. Jiang (Xishuangbanna) for their help with the spectral characterization of bract hairs' reflectance, and to K. Xu, Z. R. Li, D. G. Zhang, and M. Shi (Kunming) for assisting in fieldwork.

\section{References Cited}

Beck, E., Scheibe, R., Senser, M., and Müller, E., 1980: Estimation of leaf and stem growth of unbranched Senecio keniodendron trees. Flora, 170: 68-76.

Brewer, C. A., and Smith, W. K., 1997: Patterns of leaf surface wetness for montane and subalpine plants. Plant Cell and Environment, 20: 1-11.

Chen, Y. Z., and Lu, C. F., 2002: Freezing tolerance of calli and suspension cell cultures in alpine plant Saussurea medusa Maxim. Chinese Bulletin of Botany, 19: 219-223 (in Chinese).

Ehleringer, J., 1981: Leaf absorptance of Mojave and Sonoran Desert plants. Oecologia, 49: 366-370.

Ehleringer, J., and Mooney, H. A., 1978: Leaf hairs: effects on physiological activity and adaptive value to a desert shrub. Oecologia, 37: 183-200.

Ehleringer, J., Björkman, O., and Mooney, H. A., 1976: Leaf pubescence: effect on absorptance and photosynthesis in a desert shrub. Science, 192: 376-377.

Ehleringer, J., Mooney, H. A., Gulmon, S. L., and Rundel, P. W., 1981: Parallel evolution of leaf pubescence in Encelia in coastal deserts of North and South America. Oecologia, 49: 38-41.

Fujikawa, K., and Omori, Y., 2000: A field survey in Milke Danda and Jaljale Himal, east Nepal. Newsletter of Himalayan Botany, 26: $1-5$.

Galen, C., 2006: Solar furnaces or swamp coolers: costs and benefits of water use by solar-tracking flowers of the alpine snow buttercup, Ranunculus adoneus. Oecologia, 148: 195-201.

Hainsworth, F. R., Wolf, L. L., and Mercier, T., 1984: Pollination and pre-dispersal seed predation: net effects on reproduction and inflorescence characteristics in Ipomopsis aggregata. Oecologia, 63: 405-409.

Hedberg, O., 1964: Features of Afroalpine plant ecology. Acta Phytogeographica Suecica, 49: 1-144.

Kleier, C., 2001: Functional ecology, ecophysiology, and convergent evolution of dwarf shrub and cushion plant growth forms. Ph.D. thesis. University of California, Los Angeles, U.S.A. Ann Arbor, Michigan: UMI Dissertation Services.

Körner, Ch., 2003: Alpine plant life. Second edition. Berlin: Springer Verlag.

Körner, Ch., and Cochrane, P., 1986: Influence of plant physiognomy on leaf temperature on clear mid summer day in Snowy Mountains south-eastern Australia. Acta Oecologica Oecologia Plantarum, 4: 117-124.

Krog, J., 1955: Notes on temperature measurements indicative of special organization in arctic and subarctic plants for utilization of radiated heat from the sun. Physiologia Plantarum, 8: 836-839.

Levin, D. A., 1973: The role of trichomes in plant defense. The quarterly Review of Biology, 48(1): 3-15.

Luzar, N., and Gottsberger, G., 2001: Flower heliotropism and floral heating of five alpine plant species and the effect on flower visiting in Ranunculus montanus in the Austrian Alps. Arctic, Antarctic, and Alpine Research, 33: 93-99.

Meinzer, F., and Goldstein, G., 1985: Some consequence of leaf pubescence in the Andean giant rosette plant Espeletia timotensis. Ecology, 66: 512-520.

Miehe, G., 1991: Der Himalaya, eine multizonale Gebirgsregion. In Walter, H., and Breckle, S. W. (eds.), Ökologie der Erde, vol. 4: Spezielle Ökologie der gemäßigten und arktischen Zonen außerhalb Euro-Nordasiens. Stuttgart: G. Fisher Verlag, 181230.

Miller, G. A., 1986: Pubescence, floral temperature and fecundity in species of Puya (Bromeliaceae) in the Ecuadorian Andes. Oecologia, 70: 155-160.

Muchhala, N., and Jarrin, V. P., 2002: Flower visitation by bats in cloud forests of western Ecuador. Biotropica, 34(3): 387-395.

Obeso, J. R., 1993: Seed mass variation in the perennial herb Asphodelus albus: sources of variation and position effect. Oecologia, 93: 571-575.

Ohba, H., 1988: The alpine flora of the Nepal Himalayas: an introductory note. In Ohba, H., and Malla, S. B. (eds.), The Himalayan plants, Vol 1. Tokyo: University of Tokyo Press, $19-46$.

Pandey, S., and Nagar, P. K., 2003: Patterns of leaf surface wetness in some important medicinal and aromatic plants of western Himalaya. Flora, 198: 349-357.

Parkhurst, D. F., 1976: Effects of Verbascum thapsus leaf hairs on heat and mass transfer: a reassessment. New Phytologist, 76: 453-457.

Totland, O., 1996: Flower heliotropism in an alpine population of Ranunculus acris (Ranunculaceae): effects on flower temperature, insect visitation, and seed production. American Journal of Botany, 83: 452-458.

Tsukaya, H., and Tsuge, T., 2001: Morphological adaptation of inflorescence in plants that develops at low temperature in early spring: the convergent evolution of "downy plants." Plant Biology, 3: 536-543.

Tsukaya, H., Fujikawa, K., and Wu, S. G., 2002: Thermal insulation and accumulation of heat in the downy inflorescence of Saussurea medusa (Asteraceae) at high elevation in Yunnan, China. Journal of Plant Research, 115: 263-268.

Werner, P. A., 1976: Ecology of plant populations in successional environments. Systematic Botany, 1(3): 246-268.

Wolpert, A., 1962: Heat transfer analysis of factors affecting plant leaf temperature. Significance of leaf hair. Plant Physiology, 37: $113-120$.

Woodman, R. L., and Fernandez, G. W., 1991: Differential mechanical defense: herbivory, evapotranspiration, and leafhairs. Oikos, 60: 11-19.

Yang, Y., and Sun, H., 2006: Advances in the functional ecology of alpine and arctic plants. Acta Botanica Yunnanica, 28: 43-53 (in Chinese).

Yoshida, T., 2002: Adaptive strategies of alpine plants in Nepal. In Noshiro, S., and Rajbhanselari, K. R. (eds.), Himalayan Botany in the Twentieth and Twenty-First Centuries. Tokyo: The Society of Himalayan Botany, 105-111.

Yoshida, T., 2005: Himalayan Plants Illustrated. Tokyo: YamaKei Publishing Company.

Zhang, Y. G., 1998: Several issues concerning vertical climate of the Hengduan Mountains. Resources Science, 20: 12-19 (in Chinese). 